\title{
Psychoendocrinological studies in dwarfed children and adolescents
}

\author{
HANS-CHRISTOPH STEINHAUSEN and NIKOLAUS STAHNKE \\ From the Children's Hospital, University of Hamburg, West Germany
}

Steinhausen, H-C., and Stahnke, N. (1976). Archives of Disease in Childhood, 51, 778. Psychoendocrinological studies in dwarfed children and adolescents. Thirty-two dwarfed children and adolescents were studied clinically, by laboratory assessment, by a battery of psychological tests and a structured interview. Growth hormone deficiency was present in 16 cases, but in the remaining 16 cases there was no endocrine disease.

Dwarfed children differed from normal controls in perception, and a specific personality pattern emerged in the dwarfed children. The effects of age, sex, and socioeconomic status on personality traits were similar for dwarfs as for controls. Intelligence and personality variables were similar in dwarfs with and without endocrine disease. However, symptoms of the psychoendocrine syndrome, namely appetite and thirst disturbances, hypersensitivities, and impulse reduction, were more frequently seen among hypopituitary dwarfs. Social and coping behaviour was impaired in the majority of dwarfs. It is concluded that psychological disturbance occurring in children of small stature is a response to being small and is not attributable to any endocrine effect.

The psychology of dwarfism in children has been studied mainly within two major research areas. Using nonstructured or semistructured interviews several workers attempted to study personality and coping behaviour in dwarfed children and to some extent in family members (Martin and Wilkins, 1958; Drash, 1969; Hampson and Money, 1957; Money, 1967, 1969; Shurka and Laron, 1975; Wallis, 1961; Weber, 1971). In addition to this rather unspecific approach, others have investigated whether there are specific psychoendocrinological correlations in hypopituitarism, basing their studies on intellectual functioning (Drash and Money, 1968; Drash, Greenberg, and Money, 1968; Frankel and Laron, 1968; Pollitt and Money, 1964) and to some extent on the so-called psychoendocrine syndrome (Kind, 1962, 1963; Weber, 1971), which has been studied extensively in adults by Bleuler (1954).

No consistent theory of psychoendocrinology exists (Steinhausen, 1973), and therefore those two areas of research are open to further investigation. As most clinical workers found certain behavioural characteristics in dwarfed children, the question Received 19 January 1976. arises whether these children really differ from control children of normal stature as far as personality traits are concerned. Furthermore, the influence of factors such as age, sex, and socioeconomic status on the personality of dwarfed children is still unknown. Though intelligence in dwarfed children has been assessed in several countries, there is still no clear indication of whether intelligence is affected negatively due to hypopituitarism or whether it is statistically normal. Further, it would be useful to have a more exact measurement of intelligence than the rather unstructured test of general intelligence represented by the frequently used Wechsler Scales.

This study therefore attempts to answer these questions using reliable and valid psychological and medical methods as well as a control group design.

\section{Subjects}

Thirty-two dwarfed children with height below the 3rd centile (Tanner, Whitehouse, and Takaishi, 1966) were studied. Each child had a clinical examination, laboratory assessment, and a series of psychological tests. A semistructured interview was held with 17 children and their parents separately. Results of the psycho- 
logical tests in the study group were compared with those of a control group, made up of children from local schools having normal stature and selected to match the experimental group for age, sex, and social class (Table I). The majority of the dwarfed children were aged 9 to $14 ; 8$ adolescents aged 15 to 17 were also included in the sample.

\section{Methods}

Clinical examination. After admission to hospital a complete physical and laboratory examination was made. $X$-rays of skull, chest, and hand were taken; an electroencephalogram was obtained and all patients were seen by an ophthalmologist. Height measurements were transformed into standard deviation scores (Vince and Tanner, 1972). Skeletal maturity was estimated by comparison of $x$-rays of left hand and wrist with the atlas of Greulich and Pyle (1959).

Laboratory assessments. Thyroid stimulating hormone was assessed indirectly by determination of thyroid ${ }^{132}$ I uptake, and of serum protein-bound iodine. ACTH secretion was estimated by the oral 2-day metyrapone test with measurement of urinary excretion of 17hydroxycorticosteroids (Silber and Porter, 1954) (separate estimation of tetrahydrodesoxycortisol and tetrahydrocortisol, Bierich, Schönberg, and Eckler, 1962). Corticosteroids in plasma were measured before and after a 4-hourly infusion of $0.25 \mathrm{mg}$ (25 IU)tetracosactrin (Bierich, 1959). As a rough screening test for antidiuretic hormone deficiency the specific gravity of the first urine specimen of the day was measured on several occasions.

To evaluate growth hormone (GH) secretion, the $\mathrm{GH}$ response to insulin-induced hypoglycaemia and arginine infusion (Parker, Hammond, and Daughaday, 1967) was investigated. GH was determined by double antibody radioimmunoassay (Quabbe, 1969). The lower limit of sensitivity of this assay in our laboratory is $0.5 \mathrm{ng} / \mathrm{ml}$. The human $\mathrm{GH}$ level of a control plasma estimated in 44 assays was $2.98 \mathrm{ng} / \mathrm{ml} \pm 0.06$ SEM. The recovery of $4 \mathrm{ng}$ human $\mathrm{GH}$ added to $1 \mathrm{ml}$ plasma was $96 \% \pm 1.5$ SEM in 41 assays. A peak GH concentration of more than $5 \mathrm{ng} / \mathrm{ml}$ is considered a normal response in our laboratory (Stahnke et al., 1975).

Psychological examination. In each child intelligence and personality were studied. Intelligence was measured by means of a multifactorial test based on Thurstone's test of primary mental abilities. For the purpose of comparison with other studies, the Wechsler Scales were also used in the study group. Personality traits were assessed using a questionnaire measuring second-order factors, extraversion, and neuroticism; an unpublished scale measuring aggressiveness; and a revision of the German version of the Children's Personality Questionnaire of Cattell. Finally, each child answered a questionnaire measuring 'perceived parental behaviour', i.e. maternal and paternal support and strictness, a test of German origin.

Three main questions were posed. (1) Are there any differences in personality and intelligence between dwarfed children and normals? (2) Do age, sex, and social class influence the results of psychological testing, as carried out in our two samples? (3) Are there psychometric and behavioural characteristics in hypopituitarism which differ from those in dwarfism not caused by endocrine disease?

Statistical analysis of data was made by two-tailed t-test, and several three-way analyses of variance for type of sample (dwarfed children vs. controls), age (cut off point, 150 months), sex, and/or social class (lower class vs. middle class). As some questionnaires applied to one specific range of age only, it was possible that sample size of certain psychological variables might differ. Because of the small proportion of female dwarfs in the sample it was possible to analyse the influence of sex in only some of the psychological data.

\section{Results}

Table II summarizes some results of the clinical examination and laboratory assessment. Complete endocrine evaluation showed 16 patients to have growth hormone deficiency and the remaining 16 patients to have normal hypothalmic and pituitary function. Patients with growth hormone deficiency when compared with those with no endocrine disease had a decreased ratio of bone age to chronological age and an increased standard deviation score. However, the decreased ratio of bone age to chronological age in those patients was less pronounced than expected, because some had been treated with anabolic steroids some years before which accelerated bone age. 6 of the 16 patients

TABLE I

Comparison of dwarfed and control children

\begin{tabular}{|c|c|c|c|c|c|c|c|}
\hline & \multicolumn{3}{|c|}{ Age (m) } & \multicolumn{2}{|c|}{ Sex } & \multicolumn{2}{|c|}{ SES } \\
\hline & Mean & SD & Range & $\mathbf{M}$ & F & $\begin{array}{l}\text { Lower } \\
\text { class }\end{array}$ & $\begin{array}{c}\text { Middle } \\
\text { class }\end{array}$ \\
\hline $\begin{array}{l}\text { Dwarfs } \\
\text { Controls }\end{array}$ & $\begin{array}{l}168 \cdot 9 \\
170 \cdot 2\end{array}$ & $\begin{array}{l}32 \cdot 9 \\
30 \cdot 6\end{array}$ & $\begin{array}{l}112-214 \\
112-222\end{array}$ & $\begin{array}{l}26 \\
27\end{array}$ & $\begin{array}{l}6 \\
5\end{array}$ & $\begin{array}{l}19 \\
18\end{array}$ & $\begin{array}{l}13 \\
14\end{array}$ \\
\hline
\end{tabular}

SES, socioeconomic status. 
TABLE II

Investigations in 32 growth-retarded patients, with and without growth hormone deficiency

\begin{tabular}{|c|c|c|c|c|c|}
\hline & \multicolumn{2}{|c|}{ GH deficiency $(n=16)$} & \multicolumn{3}{|c|}{ No endocrine disease $(n=16)$} \\
\hline & Mean & SD & Mean & SD & $\mathbf{P}$ \\
\hline $\begin{array}{l}\text { Chronological age (years) } \\
\text { Bone age (years) } \\
\text { Bone age: chronological age } \\
\text { Height (SDS) } \\
\text { GH peak (ng/ml) } \\
\text { Insulin test } \\
\text { Arginine test }\end{array}$ & $\begin{array}{r}14 \cdot 43 \\
10 \cdot 49 \\
0 \cdot 71 \\
-4 \cdot 43 \\
1 \cdot 07 \\
1 \cdot 32\end{array}$ & $\begin{array}{l}3 \cdot 5 \\
3 \cdot 7 \\
0 \cdot 15 \\
1 \cdot 42 \\
0 \cdot 21 \\
0 \cdot 25\end{array}$ & $\begin{array}{r}13 \cdot 45 \\
10 \cdot 90 \\
0 \cdot 81 \\
-3 \cdot 03 \\
16 \cdot 32 \\
14 \cdot 69\end{array}$ & $\begin{array}{l}2 \cdot 0 \\
2 \cdot 1 \\
0 \cdot 12 \\
1 \cdot 02 \\
2 \cdot 27 \\
2 \cdot 73\end{array}$ & $\begin{array}{l}<0.01 \\
\text { n.s. } \\
<0.05 \\
<0.01 \\
<0.001 \\
<0.001\end{array}$ \\
\hline
\end{tabular}

SDS, standard deviation score.

with growth hormone deficiency had an isolated deficiency, though confirmation of this diagnosis will have to await the onset of puberty. Puberty had already begun in 3 ; the remaining 3 patients could not have started puberty considering their retarded bone age. The patients with no endocrine disease had constitutional delay in growth and sexual maturation, and were children with familial short stature.

Personality and intelligence differences between dwarfed children and normals. Statistical results concerning this question are given in Table III. Although a discriminant analysis for the two groups of dwarfs and controls and 12 subtests of the intelligence test was not significant, there were statistical differences $(P<0.05)$ between the groups in two subtests measuring spatial orientation and speed of closure, in which dwarfed children were inferior to controls. Among 20 personality variables (including 4 scales measuring perceived parental behaviour), 7 scales of the Children's Personality Questionnaire (CPQ) and the aggression scale discriminated significantly between the two groups. Thus dwarfed children may be labelled as less aggressive, less excitable $(\mathrm{CPQ}, \mathrm{D})$, less dominant (CPQ, E), more conscientious $(C P Q, G)$, more tender-minded $(C P Q, I)$, less shrewd (CPQ, N), more controlled (CPQ, Q3), and less tense (CPQ, Q4) than controls of normal stature.

Effect of age, sex, and social class on psychological test results. Findings concerning the second question were as follows. Age was a factor insofar as younger children displayed less word fluency $(P<0.01)$ and were less venturesome $(P<0.05)$ than older children. Another significant effect for several psychological variables was that of social class in that lower class patients scored lower in scales measuring word fluency $(P<0.05)$, flexibility of closure $(P<0.05)$, super-ego strength $(P<0.02)$, and tender-mindedness $(P<0 \cdot 01)$. The effect of sex was apparent for extraversion and aggressiveness, with girls having lower scores in both scales $(P<0.02, P<0.05$, respectively). Apart from these main effects, dwarfed girls were less extraverted than dwarfed boys $(\mathbf{P}<0 \cdot 01)$, and older dwarfed children showed less dominance than older controls $(\mathrm{P}<0 \cdot 01)$.

Psychometric and behavioural differences in two types of dwarfism. The third question was approached by means of the t-test for mean differences between hypopituitary dwarfs and dwarfs without endocrine disease. Among 35 psychological variables only one (scale $J$ of the CPQ) discriminated the two groups, indicating that hypopituitary dwarfs are less sceptical and hesistant than dwarfs with no endocrine disease $(\mathrm{P}<0.05)$.

Selected behavioural and social characteristics of the two groups of dwarfs are given in Table IV. These items come from more extended semistructured interviews of 17 dwarfed children and adolescents, not further discussed because of space limitation. The data showed a greater frequency of symptoms contributing to the psychoendocrine syndrome, namely appetite and thirst disturbances, hypersensitivities, and impulse reduction, among hypopituitary dwarfs than among dwarfs with no endocrine disease. On the other hand, social and coping behaviour was similar in the two groups. Nevertheless, dwarfism constitutes a major problem insofar as inadequate coping was present in almost three-quarters of the group. Taunting by adults was a greater problem than taunting by peers: less than one-third of the children were able to respond to adults with wit, whereas two-thirds were able to respond in this way to their peers. In the total 
TABLE III

Comparison of intelligence and personality of dwarfed children and adolescents $(d)$ with controls of normal stature (c) (analysis of variance)

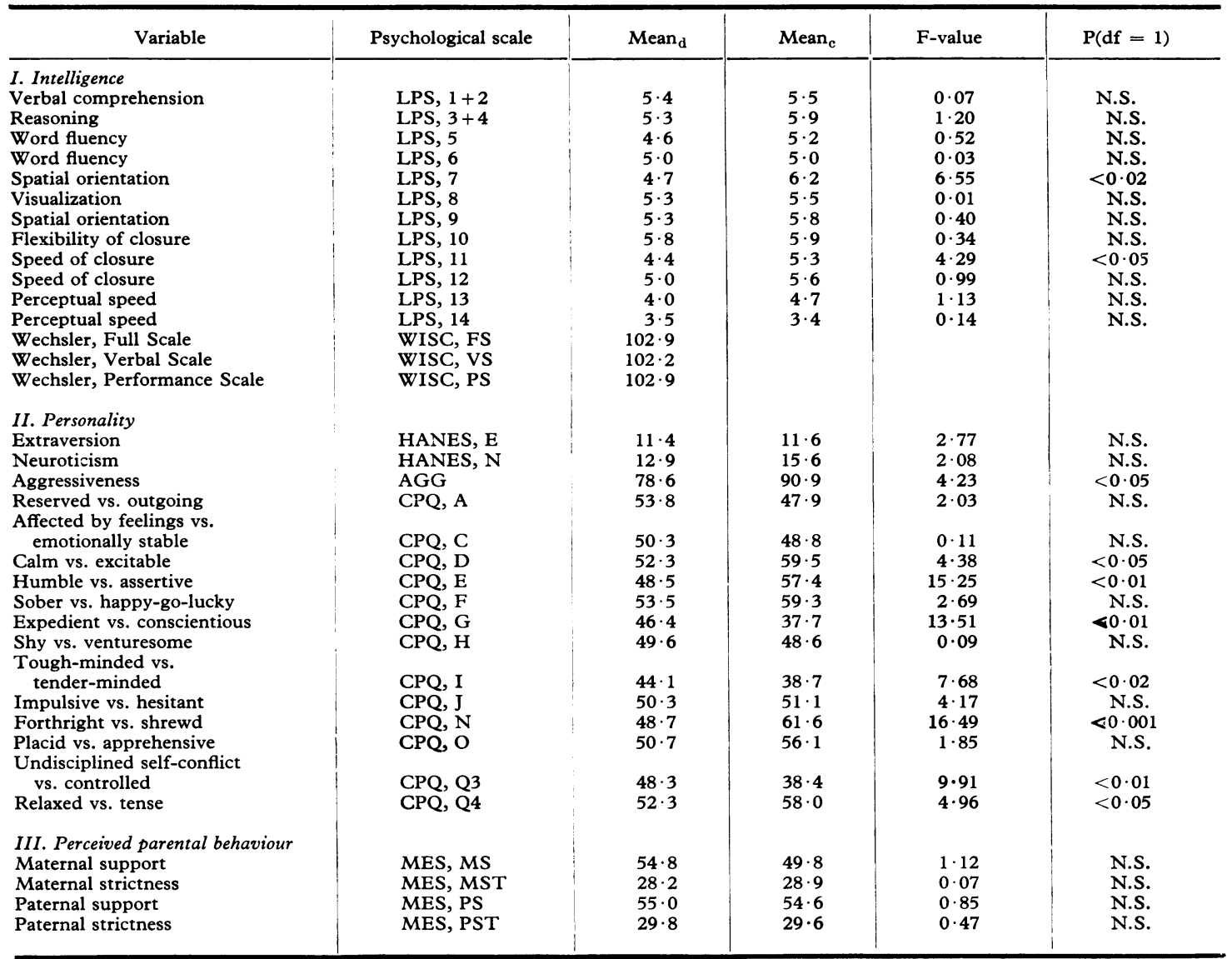

LPS, Structural Intelligence Test; WISC, Wechsler Intelligence Scale for Children; HANES, Hamburg Neuroticism Extraversion Scale; CPQ, Children's Personality Questionnaire; MES, Marburg Scales of Perceived Parental Behaviour.

group the proportion of pupils having adequate school performance was equal to that of pupils with inadequate as far as grade levels and achievement were concerned. This was also true of scholastic achievement in the two subgroups of dwarfs. However, there was a higher proportion of children without endocrine disease who were not in the grade appropriate to their age compared with the hypopituitary dwarfs.

\section{Discussion}

A psychological comparison of dwarfed children and adolescents with normals showed that several variables discriminated between the two groups.
Dwarfed children scored lower in two subtests of a multifactorial intelligence test measuring spatial orientation and speed of closure. This may be interpreted as showing that dwarfs have a different organization of perception, and corresponds to the findings of others who have observed poor visualmotor functioning among dwarfed children (Frankel and Laron, 1968; Shurka and Laron, 1975). However, there were no differences between dwarfs and controls with regard to other intelligence factors and general intelligence. Our results for the Wechsler Scales are similar to those of Money and co-workers in the US (Pollitt and Money, 1964; Drash and Money, 1968; Drash et al., 1968; 
TABLE IV

Selected behavioural and social characteristics in 17 dwarfed children (frequencies and percentages within three groups)

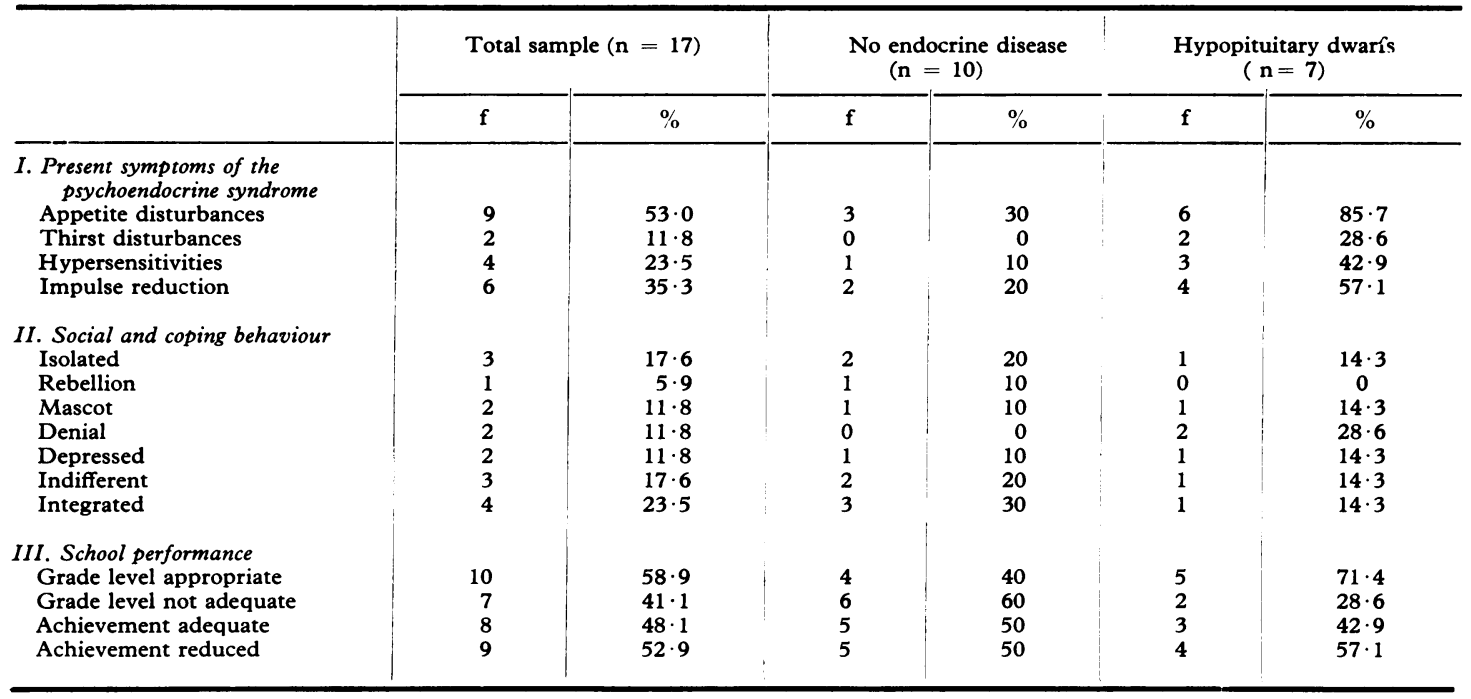

Money et al., 1967a, b), and differ from those of the Israeli investigators who studied dwarfism in a culturally different sample of Jewish-oriental origin (Frankel and Laron, 1968; Shurka and Laron, 1975). Both Money in the US and ourselves in Europe found normal general intelligence, including verbal and performance scale of the Wechsler tests, whereas the Israeli children had intelligence quotients on average below normal.

Among 16 personality factors 8 discriminated between the two groups, indicating that dwarfed children are less aggressive, less excitable, less dominant, more conscientious, more tender-minded, less shrewd, more controlled, and less tense than their peers. Thus dwarfed children may be described as living in a secluded inner world of intensified feelings, sentiments, and emotions. This conclusion agrees with the social and coping behaviour observed among the subjects whose extravert and sociable behaviour seems to be deficient. A further conclusion is that dwarfed children and adolescents should not be labelled as having neurotic personalities.

Further statistical analysis showed that the effects of age, sex, social class are almost the same for dwarfed children as for their peers without retarded growth. There were only two interaction effects indicating that sex and age are of special significance: dwarfed girls are less extraverted than dwarfed boys, and older dwarfs are less dominant than older controls. Therefore, the finding of less dominance in the whole group of dwarfs is mainly due to the proportion of older dwarfs.

Comparison of intelligence, personality, and perceived parental behaviour between dwarfed children and adolescents with and without growth hormone deficiency gave only one psychological variable differentiating the two groups, but this single effect must be regarded as a statistical chance. We therefore conclude that the personality development in dwarfed individuals is mainly a result of experiences associated with dwarfism and not due to specific endocrine deficiencies. However, there are some specific behavioural symptoms, such as disturbances of appetite and thirst, hypersensitivity, and reduced impulse which are found more commonly among hypopituitary dwarfs. These and further symptoms of the psychoendocrine syndrome were found by other European investigators (Kind, 1962, 1963; Weber, 1971). Coping and social behaviour again are often jeopardized in both groups of dwarfed children and adolescents, indicating that severe growth retardation presents a serious adaptational problem for this group of youngsters. Therefore psychological counselling, as described by several authors (Drash, 1969; Money, 1967; Steinhausen, 1973), and psychotherapy are indicated in most dwarfed children and adolescents. 


\section{Psychoendocrinological studies in dwarfed children and adolescents}

\section{REFERENCES}

Bierich, J. R. (1959). Methoden zur Bestimmung der freien Corticosteroide im plasma. Endokrinologie, 37, 25.

Bierich, J. R., Schönberg, D., and Eckler, E. (1962). Die Prüfung der corticotropen Funktion der Hypophyse mit Metopiron. I. Mitteilung. 8th Symposion der deutschen Gesellschaft für Endokrinologie, Berlin, p. 351 . Springer, Berlin.

Bleuler, M. (1954). Endokrinologische Psychiatrie. Thieme, Stuttgart.

Drash, Ph. W. (1969). Psychological counseling: dwarfism. Endocrine and Genetic Diseases of Childhood. p. 104. Ed. by L. I. Gardner. Saunders, Philadelphia and London.

Drash, Ph. W., and Money, J. (1968). Statural and intellectual growth in congenital heart disease, in growth hormone deficiency and in sibling controls. Human Growth, Body Composition, Cell Growth, Energy and Intelligence, p. 606. Ed. by D. B. Cheek. Lea and Febiger, Philadelphia.

Drash, Ph. W., Greenberg, N. E., and Money, J. (1968). Intelligence and personality in four syndromes of dwarfism. Human Growth, Body Composition, Cell Growth, Energy and Intelligence, p. 568. Ed. by D. B. Cheek. Lea and Febiger, Philadelphia.

Frankel, J. J., and Laron, Z. (1968). Psychologic aspects of pituitary insufficiency in children and adolescents with special references to growth hormone. Israel fournal of Medical Sciences, 4, 953.

Greulich, W. W., and Pyle, S. I. (1959). Radiographic Atlas of Skeletal Development of the Hand and Wrist. Oxford University Press, London.

Hampson, J. L., and Money, J. (1957). The child with disorders of physical growth. Management of the Handicapped Child, p. 173. Ed. by H. Michael-Smith. Grune and Stratton, New York.

Kind, H. (1962). Die Persönlichkeit und ihre Störungen bei praepubertal einsetzender Hypophyseninsuffizienz, speziell beim hypophysaeren Kleinund Minderwuchs. Archiv für Psychiatrie und Nervenkrankheiten, 203, 545.

Kind, H. (1963). Psychische und endokrine Funktionen und ihre Wechselwirkungen in der Pathogenese des Infantilismus beim hypophysaeren Minderwuchs. Schweizer Archiv für Neurologie, Neurochirurgie und Psychiatrie, 91, 245.

Martin, M., and Wilkins, L. (1958). Pituitary dwarfism: diagnosis and treatment. Fournal of Clinical Endocrinology and Metabolism, 18, 679 .

Money, J. (1967). Dwarfism: questions and answers in counseling. Rehabilitation Literature, 28, 134.

Money, J. (1969). Intellectual functioning in childhood endocrinopathies and related cytogenetic disorders. Endocrine and Genetic Diseases of Childhood, p. 1004. Ed. by L. I. Gardner. Saunders, Philadelphia and London.

Money, J., and Pollitt, E. (1966). Studies in the psychology of dwarfism. II. Personality maturation and response to growth hormone treatment in hypopituitary dwarfs. Fournal of Pediatrics, 68, 381.
Money, J., Drash, P. W., and Lewis, V. (1967a). Dwarfism and hypopituitarism: statural retardation without mental retardation. American Fournal of Mental Deficiency, 72, 122.

Money, J., Lewis, V., Ehrhardt, A. A., and Drash, P. W. (1967b). IQ impairment and elevation in endocrine and related cytogenetic disorders. Psychopathology of Mental Development. Ed. by J. Zubin and G. Jervis. Grune and Stratton, New York.

Parker, M. L., Hammond, J. A., and Daughaday, W. H. (1967). The arginine provocative test: an aid in the diagnosis of hyposomatotropism. Fournal of Clinical Endocrinology and Metabolism, 27, 1129.

Pollitt, E., and Money, J. (1964). Studies in the psychology of dwarfism. I. Intelligence quotient and school achievement. Fournal of Pediatrics, 64, 415.

Quabbe, H. J. (1969). Radioimmunologische Bestimmung von Wachstumshormon im Plasma des Menschen. Zeitschrift für klinische Chemie und Biochemie, 7, 259.

Shurka, E., and Laron, Z. (1975). Adjustment and rehabilitation problems of children and adolescents with growth retardation. I. Familial dwarfism with high plasma immunoreactive human growth hormone. Israel fournal of Medical Sciences, 11, 352.

Silber, R. H., and Porter, C. C. (1954). The determination of 17, 21-hydroxy-20-ketosteroids in urine and plasma. Fournal of Biological Chemistry, 210, 923.

Stahnke, N., Wiebel, J., Willig, R. P., and Blunck, W. (1975). Screening-Tests zum Ausschluss eines Wachstumshormonmangels. Monatsschrift für Kinderheilkunde, 123, 335.

Steinhausen, H. C. (1973). Psychologische Merkmale verschiedener Formen des Minderwuchses. Acta Paedopsychiatrica, 39, 278.

Tanner, J. M. Whitehouse, R. H., and Takaishi, M. (1966). Standards from birth to maturity for height, weight, height velocity, and weight velocity: British children. Archives of Disease in Childhood, 41, 454 and 613.

Vince, F. P., and Tanner, J. M. (1972). Treatment of dwarfism with HGH. Human Growth Hormone, p. 158 . Ed. by A. S. Mason. Heinemann, London.

Wallis, H. (1961). Psychopathologische Befunde bei Kindern mit hormonalem Minderwuchs. Proceedings of the 3rd World Congress of Psychiatry Montreal, p. 822. McGill University Press, Montreal.

Weber, A. (1971). Die persönliche Entwicklung hormonal behandelter hypo-physärer Zwerge im Kindes- und fugendalter. (Series Paedopsychiatrica Fasc. 3.) Schwabe, Basel and Stuttgart.

Correspondence to Dr. H-C. Steinhausen, Universitaetskinderklinik, Martinistr. 52, 200 Hamburg 20, West Germany. 